$1 \mathrm{~Hz}$. Subjects reported pain on first, fifth and tenth touch. Enhanced TS is a marker of central sensitisation and we defined the magnitude of TS as TS- $\Delta$ : highest pain value of fifth or tenth touch minus the first pain value.

We analysed whether sum scores of KL (0-128), GS (0-90), PD (0-30), number of erosive interphalangeal joints $(0-20)$ and symptom duration were associated with TS- $\Delta$ using separate models of linear regression with adjustments for age, sex and BMl.

Results: Median radiographic KL sum score was 28 (IQR 15, 44) and ultrasound sum scores (GS, PD) were $3($ IQR 1,7$)$ and $0($ IQR 0,1$)$, respectively. Median number of erosive joints was $0($ IQR 0,1$)$ and symptom duration was 6 (IQR 3, 13) years. Median TS- $\Delta$ among the participants was 1 (IQR 0, 2).

Neither KL sum score $(p=0.18)$, GS-synovitis sum score $(p=0.18)$, PD sum score $(\mathrm{p}=0.86)$, number of joints with erosive $\mathrm{HOA}(\mathrm{p}=0.078)$ nor symptom duration $(p=0.21)$ were associated with TS- $\Delta$ (table 1$)$.

Table 1 Associations between OA features and temporal summation *

\begin{tabular}{|l|l|l|}
\hline \multicolumn{3}{|c|}{$\begin{array}{c}\text { Associations between OA features and } \\
\text { temporal summation * }\end{array}$} \\
\hline & $\begin{array}{l}\text { Unstandardized beta } \\
(95 \% \mathrm{CI})\end{array}$ & P-value \\
\hline $\begin{array}{l}\text { Symptom duration } \\
\text { in years }\end{array}$ & $0.015(-0.01,0.04)$ & 0.21 \\
\hline $\begin{array}{l}\text { Kellgren-Lawrence } \\
\text { sum score }\end{array}$ & $0.007(-0.00,0.02)$ & 0.18 \\
\hline $\begin{array}{l}\text { Grey scale } \\
\text { synovitis sum score }\end{array}$ & $-0.001(-0.03,0.03)$ & 0.96 \\
\hline $\begin{array}{l}\text { Power Doppler } \\
\text { sum score }\end{array}$ & $0.001(-0.05,0.06)$ & 0.86 \\
\hline $\begin{array}{l}\text { Number of erosive } \\
\text { joints }\end{array}$ & $0.070(-0.01,0.15)$ & 0.08 \\
\hline *Adjusted for sex, age and BMI & \\
\hline
\end{tabular}

Conclusions: We found no relationship between the severity of HOA pathology and CS. This is in line with the hypothesis that factors other than OA disease severity itself contribute to CS associated pain, and that CS may be a trait in some individuals. However, it does not exclude other aspects of $\mathrm{HOA}$ as an initiator of CS in a subgroup of patients.

Disclosure of Interest: None declared

DOI: 10.1136/annrheumdis-2018-eular.1506

\section{FRI0525 ASSOCIATION BETWEEN DIETARY VITAMIN K INTAKE WITH KNEE SYMPTOMS AND BACK PAIN IN PATIENTS WITH KNEE OSTEOARTHRITIS}

Z. Liao ${ }^{1,2}$, J. Chang ${ }^{2,3}$, Z. Zhu ${ }^{2,4}$, W. Han ${ }^{2,4}$, T. Meng ${ }^{2}$, S. Zheng ${ }^{2}$, T. Winzenberg ${ }^{2}$, A. Wluka ${ }^{5}$, F. Cicuttini ${ }^{5}$, C. Ding ${ }^{2,4} \cdot{ }^{1}$ Rheumatology and Immunology Division, Third Affiliated Hospital of Sun Yat-Sen University, Guangzhou, China; ${ }^{2}$ Menzies Institute for Medical Research, University of Tasmania, Hobart, Australia; ${ }^{3}$ Department of Orthopaedics, 4th Affiliated Hospital, Anhui Medical University, Hefei; ${ }^{4}$ Clinical Research Centre, Zhujiang Hospital, Southern Medical University, Guangzhou, China; ${ }^{5}$ Department of Epidemiology and Preventive Medicine, Monash University, Victoria, Australia

Background: Vitamin $\mathrm{K}$ could be implicated in structural change of osteoarthritis $(\mathrm{OA})$, but current evidence is limited or conflicting so the association between vitamin $\mathrm{K}$ and $\mathrm{OA}$ symptoms remains unclear.

Objectives: This study aims to investigate the association of vitamin $\mathrm{K}$ intake with knee symptoms and structural features in people with knee OA.

Methods: The parent study, Vitamin D Effect on Osteoarthritis (VIDEO) study, was conducted between June 2010 and December 2013 in Tasmania and Victoria, Australia. Knee symptoms were assessed using the Western Ontario and McMaster University Index of osteoarthritis (WOMAC) and a Visual Analogue Scale (VAS) for pain. A validated Food Frequency Questionnaire (FFQ) (developed by the Cancer Council Victoria in Australia) was completed at baseline and used to determine dietary vitamin $\mathrm{K}$ intake. Knee Magnetic Resonance Imaging (MRI) scans were obtained according to a standardised protocol using a $1.5 \mathrm{~T}$ whole-body MRI unit. Cartilage volume, cartilage defects, bone marrow lesions and effusion volume were measured. The associations between vitamin $\mathrm{K}$ intake quartile and changes in clinical or MRI features were analysed using linear regressions.

Results: 261 participants were included at baseline and 213 completed 2 years of follow-up. There were no significant differences between two equal divisions with high or low level of vitamin $\mathrm{K}$ intake in term of baseline characteristics. As table 1 and figure 1 show, higher vitamin $\mathrm{K}$ intake quartiles were significantly associated with greater decrease in total WOMAC score and WOMAC function score over 24 months. Similar trends were seen in WOMAC pain score and stiffness score, though not statistically significant. There were no significant associations between baseline vitamin $\mathrm{K}$ intake and changes in total cartilage volume, cartilage defects, bone marrow lesions and effusion volume over 24 months.

Abstract FRI0525 - Table 1. Associations between vitamin $\mathrm{K}$ intake quartile and changes in clinical symptoms over 24 months

\begin{tabular}{|c|c|c|c|c|c|}
\hline & & $\begin{array}{c}\text { Value of change, } \\
\text { Mean (SD) }\end{array}$ & $\begin{array}{c}\text { Multivariable }{ }^{\star}, \beta \\
(95 \% \mathrm{Cl})\end{array}$ & $\begin{array}{c}\mathrm{P} \\
\text { value }\end{array}$ & $\begin{array}{l}\mathrm{P} \text { for } \\
\text { trend }\end{array}$ \\
\hline \multirow[t]{4}{*}{$\begin{array}{l}\text { Total WOMAC } \\
\text { Score }\end{array}$} & $\begin{array}{l}\text { Vitamin } \mathrm{K} \text { intake } \\
\text { quartile } 1\end{array}$ & $-112.9(327.7)$ & Reference: & & 0.046 \\
\hline & $\begin{array}{l}\text { Vitamin } \mathrm{K} \text { intake } \\
\text { quartile } 2\end{array}$ & $-130.0(482.6)$ & $\begin{array}{c}-3.6(- \\
165.3,158.1)\end{array}$ & 0.97 & \\
\hline & $\begin{array}{l}\text { Vitamin } \mathrm{K} \text { intake } \\
\text { quartile } 3\end{array}$ & $-270.6(403.3)$ & $\begin{array}{c}-149.8(- \\
313.8,14.2)\end{array}$ & 0.07 & \\
\hline & $\begin{array}{l}\text { Vitamin } \mathrm{K} \text { intake } \\
\text { quartile } 4\end{array}$ & $-234.4(415.5)$ & $\begin{array}{c}-122.4(- \\
281.3,36.5)\end{array}$ & 0.13 & \\
\hline \multirow[t]{4}{*}{$\begin{array}{l}\text { WOMAC Pain } \\
\text { Score }\end{array}$} & $\begin{array}{l}\text { Vitamin } \mathrm{K} \text { intake } \\
\text { quartile } 1\end{array}$ & $-30.4(81.8)$ & Reference: & & 0.33 \\
\hline & $\begin{array}{l}\text { Vitamin } \mathrm{K} \text { intake } \\
\text { quartile } 2\end{array}$ & $-32.9(115.5)$ & $3.3(-37.3,43.8)$ & 0.87 & \\
\hline & $\begin{array}{l}\text { Vitamin } \mathrm{K} \text { intake } \\
\text { quartile } 3\end{array}$ & $-74.8(103.1)$ & $\begin{array}{c}-41.1(-82.1,- \\
0.22)\end{array}$ & 0.05 & \\
\hline & $\begin{array}{l}\text { Vitamin } \mathrm{K} \text { intake } \\
\text { quartile } 4\end{array}$ & $-39.7(107.5)$ & $\begin{array}{c}-7.5(- \\
47.2,32.1)\end{array}$ & 0.71 & \\
\hline \multirow[t]{4}{*}{$\begin{array}{l}\text { WOMAC } \\
\text { Function Score }\end{array}$} & $\begin{array}{l}\text { Vitamin } \mathrm{K} \text { intake } \\
\text { quartile } 1\end{array}$ & $-71.4(241.2)$ & Reference: & & 0.03 \\
\hline & $\begin{array}{l}\text { Vitamin } \mathrm{K} \text { intake } \\
\text { quartile } 2\end{array}$ & $-82.8(339.4)$ & $\begin{array}{c}-5.7(- \\
120.3,108.8)\end{array}$ & 0.92 & \\
\hline & $\begin{array}{l}\text { Vitamin } \mathrm{K} \text { intake } \\
\text { quartile } 3\end{array}$ & $-168.7(275.2)$ & $\begin{array}{c}-94.7(- \\
210.9,21.5)\end{array}$ & 0.11 & \\
\hline & $\begin{array}{l}\text { Vitamin } \mathrm{K} \text { intake } \\
\text { quartile } 4\end{array}$ & $-172.5(301.8)$ & $\begin{array}{l}-104.1(- \\
216.6,8.5)\end{array}$ & 0.07 & \\
\hline
\end{tabular}

*Adjusted for age, sex, BMl and vitamin D intervention group
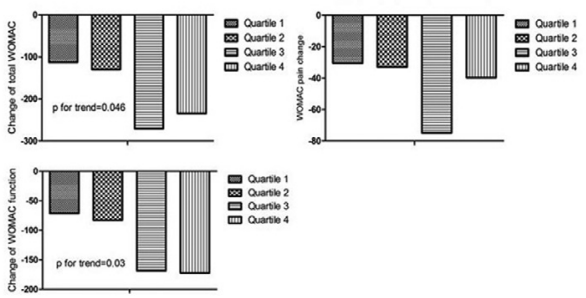

Figure 1 Change in WOMAC score over 24 months among those with different vitamin $\mathrm{K}$ intake quartiles

Conclusions: Higher baseline vitamin $\mathrm{K}$ intake was associated with decreased knee symptoms over 24 months in patients with knee OA. These suggest that vitamin $\mathrm{K}$ intake may be beneficial for knee OA.

Disclosure of Interest: None declared

DOI: 10.1136/annrheumdis-2018-eular.6807

\section{FRI0526 THE IMPACT OF DISEASE CHARACTERISTICS IN KNEE AND HIP OSTEOARTHRITIS ON RECOMMENDATIONS FOR JOINT REPLACEMENT}

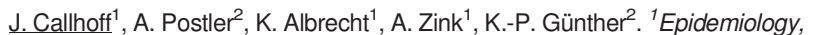
German Rheumatism Research Centre, Berlin; ${ }^{2}$ University Center of Orthopedics and Traumatology, University Medicine Carl Gustav Carus Dresden, TU Dresden, Dresden, Germany

Background: Joint replacement in osteoarthritis $(O A)$ is a major reason for hospitalisation in Germany. ${ }^{1}$

Objectives: Which factors are associated with recommendations for joint replacement in patients with symptomatic hip and/or knee OA?

Methods: A total of 9734 persons, insured in a large statutory health insurance in Germany (Barmer), who had a diagnosis of OA (ICD-10 codes M15 [polyarthrosis], M16 [coxarthrosis] or M17 [gonarthrosis]) in at least two quarters in 2014 were randomly selected, stratified by age, sex and diagnosis (M15/M16/M17) They were contacted by mail and asked to complete a questionnaire regarding sociodemographics, health behaviour, the Western Ontario and McMaster Universities Osteoarthritis Index (WOMAC, 0: no impairment- 100: extreme pain/stiffness/difficulty) and whether they had ever discussed total joint replacement (TJR) surgery with a physician. Patient-reported outcomes of the responders $(n=3,564)$ were linked to claims data on prescriptions of pain medication and physical therapy. Persons with a diagnosis of $M 15(n=1,212)$ were excluded from the present analysis. Patients who reported pain in the corresponding joints were analysed in three groups: OA of the knee, of the hip or of both. Logistic regression models 
were used to assess which parameters (age, sex, $\mathrm{BMI}>30$, prescription of opioids or physical therapy, WOMAC, whether the OA was mainly treated by an orthopaedist) were associated with having discussed a TJR.

Results: Of 2352 persons with knee or hip OA, 932 had symptomatic OA of the knee, 478 of the hip, 94 of both, and 848 did not report pain in the relevant joint(s) Mean age was 64 to 67 years, $63 \%$ to $68 \%$ were female and mean BMI was high, especially in patients with knee OA $\left(29 \mathrm{~kg} / \mathrm{m}^{2}\right) .54 \%-74 \%$ had considerable impairment (WOMAC>39). $72 \%-83 \%$ had any pain medication, $12 \%-25 \%$ opioids and $33 \%-46 \%$ physical therapy. $63 \%-72 \%$ were treated by orthopaedists and $45 \%-50 \%$ had discussed TJR. In knee as well as hip and knee OA male sex and an orthopaedist as main treating physician was associated with having discussed a TJR (table 1). Age, WOMAC and opioid prescription was only associated with a higher OR of discussing a TJR in knee OA.

Abstract FRI0526 - Table 1. Results from multivariable logistic regression models showing parameters associated with having discussed TJR.

\begin{tabular}{|c|c|c|c|}
\hline & $\begin{array}{l}\text { OR for knee and hip OA } \\
(\mathrm{n}=94), 95 \% \mathrm{Cl}\end{array}$ & $\begin{array}{l}\text { OR for hip OA } \\
(n=478), 95 \% \mathrm{Cl}\end{array}$ & $\begin{array}{l}\text { OR for knee OA } \\
(n=932), 95 \% \mathrm{Cl}\end{array}$ \\
\hline $\begin{array}{l}\text { Orthopaedist } \\
\text { is treating }\end{array}$ & $7.2(1.9,26.8)$ & $1.6(0.9,2.8)$ & $1.7(1.1,2.6)$ \\
\hline $\begin{array}{l}\text { Age, per } \\
10 \text { years }\end{array}$ & $1.0(0.56,1.8)$ & $1.0(0.8,1.3)$ & $1.2(1.1,1.5)$ \\
\hline $\mathrm{BMI} \leq 30$ vs $>30$ & $0.9(0.2,3.6)$ & $1.0(0.6,1.8)$ & $1.3(0.9,2.0)$ \\
\hline Male vs female & $5.3(1.3,21.8)$ & $1.1(0.6,1.8)$ & $1.5(1.1,2.2)$ \\
\hline $\begin{array}{l}\text { WOMAC, per } \\
10 \%\end{array}$ & $1.3(0.8,1.9)$ & $1.1(0.9,1.3)$ & $1.3(1.2,1.5)$ \\
\hline Opioids & $0.8(0.1,6.1)$ & $0.5(0.2,1.2)$ & $1.9(1.0,3.3)$ \\
\hline $\begin{array}{l}\text { Physical } \\
\text { therapy }\end{array}$ & $1.1(0.3,3.3)$ & $1.1(0.6,2.0)$ & $1.2(0.8,1.7)$ \\
\hline
\end{tabular}

Conclusions: Disease burden is highest in persons with concomitant knee and hip OA. Men are more likely to discuss TJR with their physician, but not in hip OA. Disease burden and treatment recommendations were only weakly associated. Therefore, other factors may be more important when considering surgery in knee and hip OA.

\section{REFERENCE:}

[1] Destatis W. Statistisches Bundesamt Gesundheit. Diagnosedaten der Patienten und Patientinnen in Krankenhäusern (einschl. Sterbe- und Stundenfälle). Fachserie 12 Reihe 6.2.1 - 2016.

Acknowledgements: This study was funded by the German Federal Ministry of Education and Research (01EC1405).

Disclosure of Interest: None declared

DOI: 10.1136/annrheumdis-2018-eular.2163

\section{FRI0527 EFFICACY OF BIO-OPTIMISED CURCUMA EXTRACT (FLEXOFYTOL ${ }^{\circledR}$ ) FOR PAINFUL KNEE OSTEOARTHRITIS: DATA FROM COPRA, A MULTICENTER RANDOMISED CONTROLLED STUDY}

Y. Henrotin $^{1}$, M. Malaise ${ }^{2}$, R. Wittoek ${ }^{3}$, K. Devlam ${ }^{4}$, J.-P. Brasseur ${ }^{5}$, F. Luyten ${ }^{6}$,

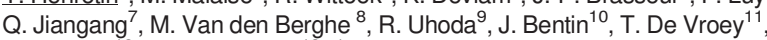
L. Erpicum ${ }^{12}$, Y. Dierckxsens ${ }^{13}$. ${ }^{1}$ Bone and Cartilage Research Unit, University of Liège; ${ }^{2}$ Rheumatology department, CHU Sart-Tilman, Liège; ${ }^{3}$ Rheumatology department, UZ Gent, Gent, ${ }^{4}$ Rheumatology department, ZNA Jan Palfijn, Merksem; ${ }^{5}$ Rheumatology department, CHU UCL Namur, Yvoir, ${ }^{6}$ Rheumatology department, University Hospitals Leuven, Leuven; ${ }^{7}$ Rheumatology and physical medicine department, Hôpitaux Iris Sud, Bruxelles; ${ }^{8}$ Rheumatology department, Algemeen Stedelijk Ziekenhuis, Aalst, ${ }^{9}$ Physical medicine and rehabilitation department, Centre Hospitalier du Bois de l'Abbaye, Seraing; ${ }^{10}$ Rheumatology department, CHU Brugmann, Bruxelles; ${ }^{11}$ Physical medicine, UZA, Antwerpen; ${ }^{12}$ Private practice, Anthisne; ${ }^{13}$ Tilman SA, Baillonville, Belgium

Background: Flexofytol is a Curcuma Longa extract with an increased bioavailibility (bio-optimised) by mixing curcuma extract with polysorbate.

Objectives: To demonstrate the effects of Flexofytol on OA symptoms and soluble biomarkers.

Methods: 141 patients with symptomatic knee OA (mean age 61.8 years [min.45-max.86]; 80.1\% female; mean $\mathrm{K}$ and $\mathrm{L}$ grade of the knee 2.4; mean BMI $29.7 \mathrm{~kg} / \mathrm{m}^{2}$ ) were randomised in a prospective double blinded, 3 parallel groups, comparative and multicenter, study (NCT02909621). At inclusion, all patients took pain killers or anti-inflammatory drugs which were authorised during the study. Patients received 6 months continuous treatment with either high dose Flexofytol ( $n=49,140.01 \mathrm{mg}$ Curcuma longa L. extract/treatment), low dose Flexofytol ( $n=47,93.34 \mathrm{mg}$ Curcuma longa L. extract/treatment) or placebo $(n=45$, Sunflower seed oil fill ingredient). Each treatment corresponded to 3 oral capsules two times a day to respect the blinding. All patients had clinical assessment (knee pain, knee function and patient global assessment of disease activity [PGADA]) and blood sampling for biomarkers measurements (usCRP and sColl2-1) at baseline (T0), 1 month (T1), 3 months (T3) and 6 months (T6). Additionally, patient compliance, satisfaction and tolerance were assessed at each timepoin following baseline. Primary outcome was the change at 3 months versus baseline in type II collagen degradation -specific biomarker SColl2-1 and VAS PGADA

Results: Comparison of time evolution curves showed that SColl2-1 levels were lower in the treated groups but differences were not significant. The decrease in PGADA overtime was significantly more important in low dose group than in pla cebo group only at the 1 month evaluation timepoint (low dose $\triangle T 1-T 0$, $-12,5 \mathrm{~mm}$ vs placebo $\triangle \mathrm{T} 1-\mathrm{T} 0,-2 \mathrm{~mm}, \mathrm{p}=0.035)$. Further, the knee pain relie was significantly higher in low dose group at T1 and T3 than in placebo (low dose $\triangle \mathrm{T} 1-\mathrm{T} 0,-16.5 \mathrm{~mm}$ vs placebo $\triangle \mathrm{T} 1-\mathrm{T} 0,-4 \mathrm{~mm} \mathrm{p}=0.046$; low dose $\triangle \mathrm{T} 3-\mathrm{T} 0$, $-36.5 \mathrm{~mm}$ vs placebo $\triangle \mathrm{T} 3-\mathrm{T} 0,-8 \mathrm{~mm} \mathrm{p}=0.043)$. No difference was observed at T6. No differences were seen for any parameter when the high dose group was compared with the placebo group at any time point. The global KOOS score and its subscales significantly decreased overtime but changes were comparable in each group. Additionally, patient compliance was good and patient satisfaction remained stable overtime in each group. The ratio of patients with adverse events $(A E)$ related to the product were similar in placebo and treated groups but the number of $A E$ linked to the product was higher in the high dose group than in placebo $(p=0.012)$

Conclusions: Flexofytol, at a low dose, induced a rapid symptomatic relief on knee pain and a beneficial effect on the patient assessment of disease. This study also provides information on the dose to use and the design of a larger phase III clinical trial.

Disclosure of Interest: Y. Henrotin Consultant for: Tilman SA, M. Malaise: None declared, R. Wittoek: None declared, K. Devlam: None declared, J.-P. Brasseur: None declared, F. Luyten: None declared, Q. Jiangang: None declared, M. Van den Berghe : None declared, R. Uhoda: None declared, J. Bentin: None declared T. De Vroey: None declared, L. Erpicum: None declared, Y. Dierckxsens Employee of: Tilman SA

DOI: 10.1136/annrheumdis-2018-eular.4820

\begin{tabular}{|l|l}
\hline FRI0528 & LONG-TERM EFFECTS OF VITAMIN D \\
& SUPPLEMENTATION AND MAINTAINING VITAMIN D \\
& SUFFICIENCY ON KNEE OSTEOARTHRITIS OVER 5 \\
& YEARS
\end{tabular}

B.S. Eathakkattu Antony ${ }^{1}$, S. Zheng ${ }^{1}$, J. Burgess ${ }^{2}$, C. Ding ${ }^{1} .{ }^{1}$ Menzies Institute for Medical Research, University of Tasmania; ${ }^{2}$ Dept of Endocrinology, Royal Hobart Hospital, Hobart, Australia

Background: Epidemiological studies suggest that vitamin D deficiency is associated with knee symptoms and structural progression of knee osteoarthritis (OA). However, randomised controlled trials (RCTs) failed to demonstrate a significant effect of vitamin D supplementation on OA, probably due to selecting OA participants with and without vitamin D deficiency, short duration of follow-up and a large proportion of participants in the placebo group reaching vitamin D sufficiency $(61.3 \%$ of patients in the placebo group achieved a serum $25(\mathrm{OH}) \mathrm{D}$ level of $>60 \mathrm{nmol} / \mathrm{L}$ at 3 months of a clinical trial).

Objectives: To examine whether those maintaining sufficient serum vitamin $D$ levels over 5 years had reduced knee symptoms compared with those who did not maintain adequate vitamin $D$ levels in patients with knee OA. We also explored the effect of 2 year vitamin D supplementation on knee symptoms compared to placebo after 3 years of cessation of treatment.

Methods: Participants with symptomatic knee OA and low 25-hydroxyvitamin D [25(OH)D] (12.5-60 nmol/L) were randomly assigned to receive monthly treatment with oral vitamin D3 (50 $000 \mathrm{IU} ; n=209)$ or an identical placebo $(n=204)$ for 2 years. 172 participants who enrolled in the study from Hobart were followed up after 3 years ( 5 years from baseline) of the cessation of the treatment to assess knee symptoms and vitamin D levels. Participants were classified as maintaining sufficient vitamin $D$ group if they maintained serum $25(\mathrm{OH}) \mathrm{D}>50 \mathrm{nmol} / \mathrm{L}$ at month 3,24 and $60(n=79)$, and not maintaining sufficient vitamin $D$ group $(25(O H) D \leq 50$ $\mathrm{nmol} / \mathrm{L}$ at month 3,26 and $60, \mathrm{n}=62$ ) groups. Knee symptoms were assessed at baseline, 3, 6, 12, 24 and 60 month using Western Ontario and McMaster Univer sities Osteoarthritis Index (WOMAC).

Results: The level of $25(\mathrm{OH}) \mathrm{D}$ dropped in the vitamin $\mathrm{D}$ group $(87.0 \mathrm{nmol} / \mathrm{L}$ to $53.3 \mathrm{nmol} / \mathrm{L})$ and slightly increased $(53.3 \mathrm{nmol} / \mathrm{L}$ to $61.7 \mathrm{nmol} / \mathrm{L})$ in the placebo group 3 years after the cessation of the treatment. Knee pain increased from the end of the study to 5 years of follow-up in the treatment (81.8 to 91.7 ) and placebo (75.8 to 101.1 ) groups. $16.7 \%$ of the participants in vitamin $D$ and $18.5 \%$ of the participants in placebo group underwent total knee replacement (TKR) surgery There were no significant differences in WOMAC symptoms, TKR rates or change in symptoms between Vitamin D and placebo groups after 3 years of cessation of the supplementation. 